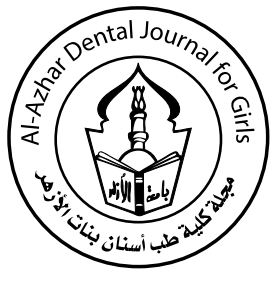

\title{
Comparative Study Between Nasogastric (Ryle) Feeding and Oral Feeding Post- Cleft Palate Repair
}

\author{
Mohamed M. Shahin ${ }^{(1)}$ and Yousry Abdelsalam(1)
}

Codex : 02/1610

dentaljournal.forgirls@yahoo.com

\section{KEYWORDS}

Palatoplasty,

nasogastric,

oral,

analgesia

\begin{abstract}
Background: feeding after surgical correction of cleft palate is an important topic; the method of feeding usually affects the surgery outcome and stress of operation in infants. However, no consensus on the method of feeding for children with cleft palate either pre-or post-operative correction. Aim of the work: to investigate the effect of nasogastric tube (NGT) feeding compared with oral feeding on children in the first 48 hours after primary cleft palate repair. Patients and methods: The study was carried out at Al-Azhar University Hospital (Pediatric Surgery Unit);Damietta and specialized kids hospital during the period from January 2015 to Jun 2016. It included 36 children presented for primary repair of cleft palate. All were undergoing full history taking, clinical examination and laboratory investigations to prepare them for surgical intervention. Those patients were divided into 2 equal groups, each group had 18 patients.Then, after intervention, they followed up to examine the effect of method of feeding either by (NGT) (group 1) or oral route (group 2) on the outcome of surgery and postoperative analgesia requirements. Results: both groups were comparable as regard to demographic characteristics, amount of intraoperative fluids and required analgesia and for postoperative surgical outcome and complications. However, there was statistically significant decrease of Postoperative morphine, paracetamol and Ibuprofen in NG feeding group when compared to oral feeding group $(0.13 \pm 0.08$, $32.50 \pm 15.55,14.44 \pm 8.72$ vs $0.23 \pm 0.13,51.66 \pm 28.43$, and $26.38 \pm 14.43$ respectively). Also, there was significant decrease of number of pain episodes in NGT feeding group when compared to oral feeding group $(3.17 \pm 2.03$ vs $4.77 \pm 2.86)$. On the other hand, there was statistically significant increase of the amount of postoperative feeding in NGT feeding when compared to oral feeding group (137.22 \pm 13.52 vs $59.72 \pm 18.74$ ) Finally, the total duration of hospital stay was significantly shortened in NGT feeding group when compared to oral feeding group (47.55 \pm 15.33 vs $78.66 \pm 18.04$ hours). Conclusion: NGT feeding is effective when compared to oral feeding post-palatoplasty as it increases consumption of foods and reduce postoperative analgesia requirements.
\end{abstract}

1. Pediatric Surgery unit - Anesthesia department, Al-Azhar Faculty of Medicine, Damietta 


\section{INTRODUCTION}

Cleft lip and palate (CLP) are congenital malformations which affect the lip, palate, or both. It occurs due to errors in the facial fusion process during embryonic life due to alterations in the normal development of the primary and/or secondary palate ${ }^{(1)}$.

Feeding in the cleft lip and palate is a major, continued challenge that faces caretakers and surgeons. The mother-child bond usually developed during the process of feeding time. In addition, the infant also develops the complex oral-motor skills required for future complex feeding accommodation and speech development. Thus, adequate feeding is of utmost importance for infant development and growth. Young and colleagues reported that, about 97\% of parents thought that, they must discuss feeding challenges of cleft infants critically, and about $95 \%$ thought it was critical to have a guidance of breast or bottle feeding. In the same study, only $55 \%$ of parents reported having feeding guidance during the cleft evaluation and $40 \%$ of parents were not informed of the potential feeding difficulties ${ }^{(2)}$.

Many studies have reported extensively on feeding difficulties in infants with cleft lip and/ or palate. It is, therefore essential to address the feeding problems of children with oro-facial cleft ${ }^{(3)}$.

Mizuno et al. showed that the sucking pattern of infants with non-syndromic complete unilateral cleft lip and palate or a cleft of the soft and hard palates differed from their matched peers without cleft $^{(4)}$.

Many methods have been adopted to meet this challenge. According to Gopinath and Muda among infants with cleft palate, $76.5 \%$ were bottle-fed and $69.2 \%$ were spoon-fed. Spoon-feeding is the most common feeding method practiced by parents of infants with cleft palate ${ }^{(5)}$.

Babies with a cleft palate had been found to take semi-solid food with greater ease than liquids, due to more control over solid food. This is especially true following a surgical repair of the palate ${ }^{(6)}$.
Sommerlad and his colleagues stated that, babies who have had palatoplasty need to establish immediate feeding to meet their nutritional needs. However, attempting to feed fluids to babies' post-palatoplasty is associated with fraught due to difficulties of feeding such infants as they often gag, choke, hold their breath and scream. Insisting babies to feed may lead to feeding aversions, aspiration pneumonia, nausea and vomiting ${ }^{(7-8)}$.

On the other hand, nasogastric tube (NGT) offered a way to overcome these complications. (NGT) is simple, economical, generally safe and usually well tolerated. In addition, beside nutritional substance, medicine (such as antibiotics and analgesics) can be provided by (NGT) ${ }^{(9-10)}$. However, long duration of feeding with nasogastric tube may be associated with difficulties in returning to normal feeding pattern, due to inactivity of muscles of swallowing.

The present study was designed to compare between oral feeding (spoon or syringe) and (NGT) feeding post-surgical repair of cleft palate.

The (FLACC) tool was used to assess the babies' pain levels, as described by Merkel et al. to examine the babies' analgesic requirements and length of stay. Analgesia was reduced depending on clinical need $^{(11)}$.

\section{PATIENTS AND METHODS}

The study was carried out at Al-Azhar University Hospital (Pediatric Surgery Unit)-Damietta and specialized kids hospital during the period from January 2015 to Jun 2016. It included 36 children presented for primary repair of cleft palate.

Exclusion criteria: Infants were excluded if they had any feeding difficulties, hemoglobin concentration $<10 \mathrm{~g} / \mathrm{dl}$, upper respiratory tract infection; or if either nasogastric tube (first group) or opioid analgesia were contraindicated.

The study protocol was approved by local research and ethics committee of Al-Azhar Faculty of Medicine; the study protocol was 
explained to all guardians and their informed consent for participation in the study was obtained. Confidentiality and the right to withdraw from the study at any point of time were guaranteed.

Then all included children were divided randomly (closed envelope method; the envelope was opened at the end of surgery to show a number of 1 or 2; 1 for nasogastric tube ( NGT) feeding and 2 for oral feeding for one of two groups:

Surgical intervention: infants in both groups received the same anesthetic management. Anesthesia was induced and maintained with sevoflurane. Tracheal intubation was assisted with

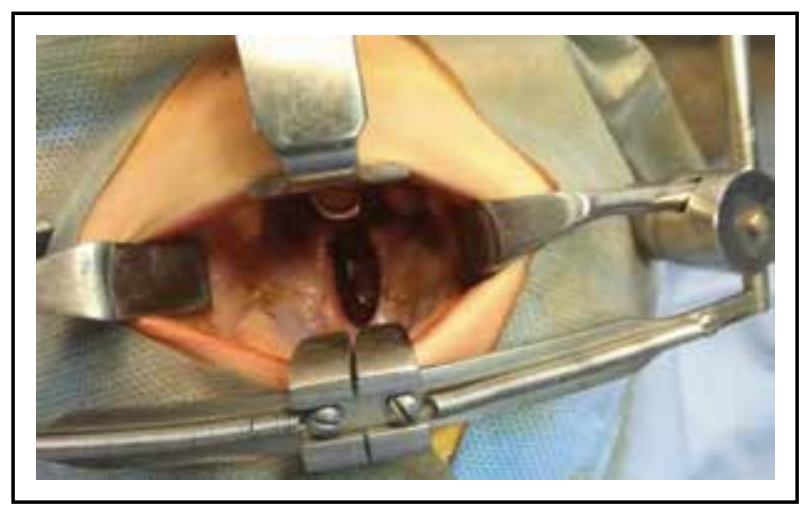

Fig. (1) Preoperative cleft palate

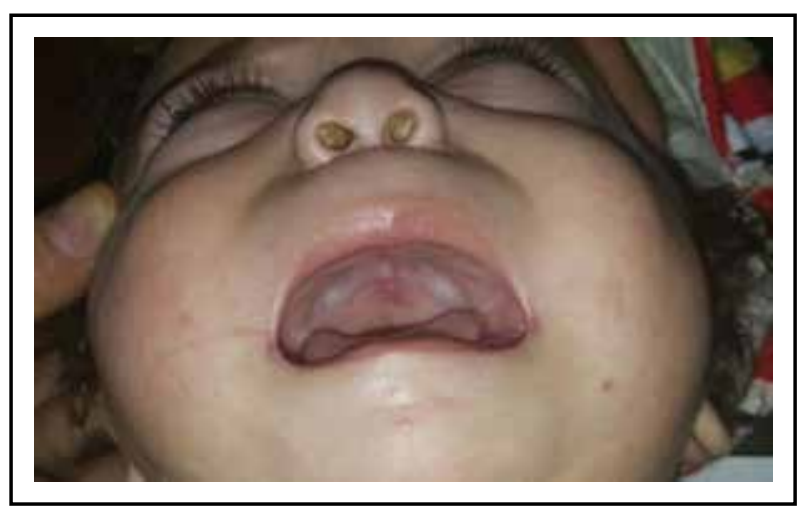

Fig. (3) 4 weeks postoperative view with complete healing (group 1) a single dose of atracurium $(0.5 \mathrm{mg} / \mathrm{kg})$. Infants received mechanical ventilation throughout surgery. Intra-operative analgesia included intravenous fentanyl (3-4 micrograms $/ \mathrm{kg})$, intravenous paracetamol $(15 \mathrm{mg} / \mathrm{kg})$ and infiltration of the palatal tissues with local anesthetic (mixture of lidocaine $0.5 \%$ with adrenaline 1: 200,000). All infants were operated by the same surgical technique involving radical repositioning and reconstruction of the soft palate musculature. If lateral releasing incisions were required, this was documented.

Complete/incomplete unilateral or bilateral cleft palates were repaired with von Langenbeck palatorraphy.

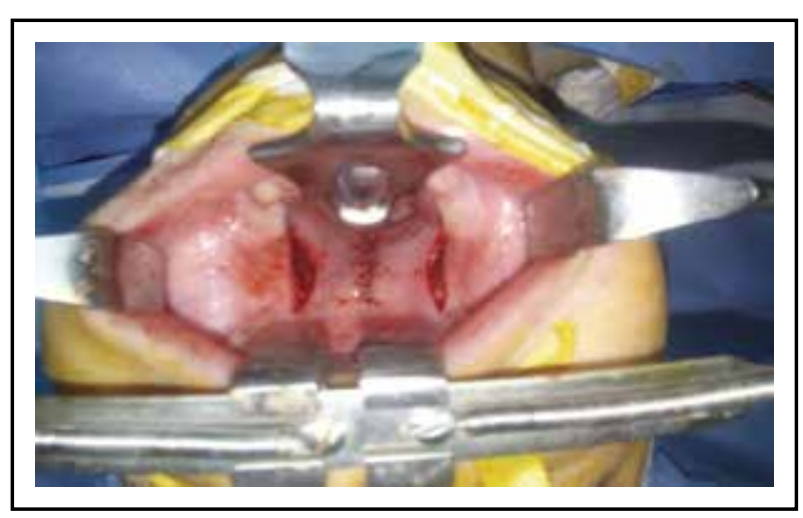

Fig. (2) Intraoperative view

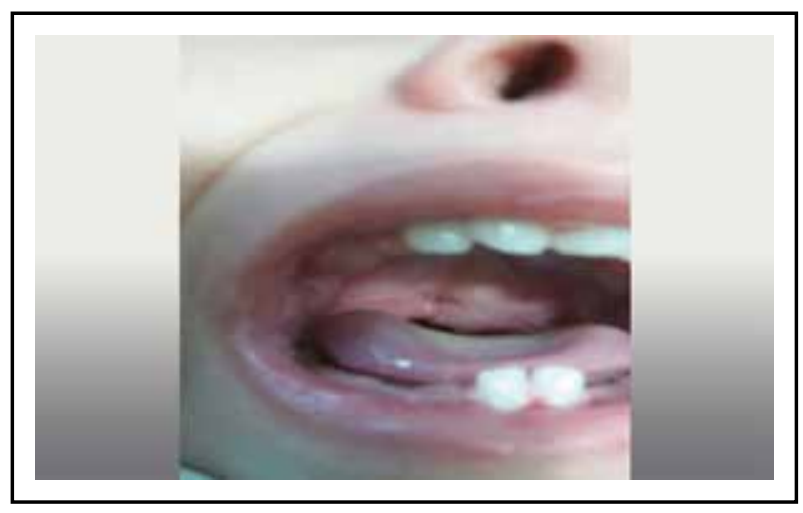

Fig. (4) 6 weeks postoperative view with uvular dehiscence (group 2) 
Towards the end of the surgery or immediately after awakening, pain was relieved with intravenous morphine and doses were decided according to the anesthetist judgment. Post-operatively, paracetamol and ibuprofen were administered regularly $(20 \mathrm{mg} /$ $\mathrm{kg}$ every six hours and $5 \mathrm{mg} / \mathrm{kg}$ every eight hours, respectively). In addition, intravenous morphine was administered on demand by using use of the face, legs, activity, cry and Consolability (FLACC) pain assessment scoring system, and the aim was to maintain pain scores of four or less. An episode of breakthrough pain was defined as a FLACC score of greater than four: these episodes were managed with analgesia, feeding or both according to clinical judgment.

Infants in the first group were managed by post-operative (NGT) feeding (size 10Fr). At the start, gag test was performed and then babies were given $50 \mathrm{ml}$ of milk feed in recovery, and returned to the ward to continue with feeds every three to four hours. Infant's meal consisted of a milk drink, and semi-solid cereal or baby rice. The tube is then removed 2 days post-operatively.

In oral feeding group, infants were fed by syringe, spoon and feeding cup which ever tolerated on demand following return to the ward. In addition, at the work the authors examine the babies' analgesic requirements and length of stay. The (FLACC) tool was used to assess the babies' pain levels, as described by Merkel et al., Analgesia was reduced depending on clinical need.

\section{Interpreting the FLACC Score}

Each category is scored on the $0-2$ scale, which results in a total score of $0-10$.

$0_{-}$Relaxed and comfortable

4-6 _ Moderate pain

1-3 _ Mild discomfort

$7-10$ _ severe discomfort or pain or both
In both groups, oral hygiene was maintained by regular palate rinses after each feed and particularly after any regurgitation or vomit. Palate rinses were carried out even if the feeds, antibiotics and analgesia were administered via nasogastric tube.

Outcome measures included the total morphine consumption in the first 24 hours and this comprised the initial dose administered by the anesthetist plus the total dose administered during the first 24 hours. In addition, the number and timing of painful episodes (FLACC >4) in each child and the volumes of intravenous fluid and enteral feed received. Furthermore, any problems related to feeding were recorded.

Finally surgical outcome for cleft palate repairs, was judged based on the integrity of the closure, i.e., on the presence or absence of fistula. The outcome was good when there was no postoperative fistula at the operative site, fair or poor respectively when the resultant fistula was less or more than $1 \mathrm{~cm}$ in greatest diameter, respectively. The fistula size was determined by using a calibrated and validated Vernier caliper ${ }^{(12)}$

\section{Statistical data analysis}

Data was analyzed using the SPSS for Windows (version 22.0; IBM ${ }^{\circledR}$ SPSS ${ }^{\circledR}$ Inc., Chicago, IL) statistical software package and presented in descriptive and tabular forms. Test of significance was used as appropriate (e.g. student (t) test for comparison between two means, Chi square or Mann-Whitney $\mathrm{U}$ test for categorical variables). $\mathrm{P}$ value was set at $<0.05$.

\section{RESULTS}

In the present work, both nasogastric feeding and oral feeding groups were comparable as regard to age, sex, gestational age (GA) at delivery, prematurity, birth weight and positive family history. Age ranged from 7 to 12 months; the mean age in NGT feeding group was $8.83 \pm 1.38$ compared to $8.94 \pm 1.25$ in oral feeding group. Males represented $22.2 \%$ vs $27.8 \%$ of NGT and oral feeding groups 
respectively. The mean GA at delivery was 38.05 in NGT feeding group compared to $37.72 \pm 1.60$ in oral feeding group. However, prematurity was reported in $16.7 \%$ and $22.7 \%$ in NGT and oral feeding groups respectively. The mean birth weight was $3103.88 \pm 150.54$ in NGT feeding group and $3076.66 \pm 155.42$ in oral feeding group. Finally, positive family history was reported in 1 and 2 cases in NGT and oral feeding groups (table 1).

As regard to intraoperative data, both groups were comparable as regard to intra-operative(IO) fluids, IO fentanyl and IO morphine $(30.88 \pm 3.66$, $3.11 \pm 0.27,0.12 \pm 0.05$ in NGT feeding group, compared to $30.16 \pm 3.68,3.02 \pm 0.37$, and $0.17 \pm 0.09$ respectively in oral feeding group). However, there was statistically significant decrease of Postoperative morphine, paracetamol and ibuprofen in NGT feeding group when compared to oral feeding group $(0.13 \pm 0.08,32.50 \pm 15.55,14.44 \pm 8.72$ vs $0.23 \pm 0.13$, $51.66 \pm 28.43$, and $26.38 \pm 14.43$ respectively). In addition, there was statistically significant decrease of number of pain episodes in NGT feeding group when compared to oral feeding group $(3.17 \pm 2.03 \mathrm{vs}$ $4.77 \pm 2.86$ ). on the other hand, there was statistically significant increase of the amount of postoperative feeding in NGT feeding when compared to oral feeding group $(137.22 \pm 13.52$ vs $59.72 \pm 18.74)$. Finally, postoperative fluids were needed in only oral feeding group and ranged from 7 to $11 \mathrm{ml} / \mathrm{kg}$ with a mean of $9.05 \pm 1.30 \mathrm{ml} / \mathrm{kg}$ (table 2).

Table (1) Comparison between NGT and oral feeding groups as regard patient characteristics

\begin{tabular}{|c|c|c|c|c|}
\hline Variable & NGT feeding & Oral Feeding & Test & P value \\
\hline Age (months) & $8.83 \pm 1.38 ; 7-12$ & $8.94 \pm 1.25 ; 7-11$ & 0.25 & $0.80(\mathrm{~ns})$ \\
\hline $\operatorname{Sex}(M / F)(n, \%)$ & $4(22.2 \%) / 14(77.8 \%)$ & $5(27.8 \%) / 13(72.2 \%)$ & 0.14 & $0.70(\mathrm{~ns})$ \\
\hline GA at delivery (weeks) & $38.05 \pm 1.39 ; 35-40$ & $37.72 \pm 1.60 ; 35-40$ & 0.66 & $0.51(\mathrm{~ns})$ \\
\hline Prematurity $(\mathrm{n}, \%)$ & $3(16.7 \%)$ & $4(22.7 \%)$ & 0.17 & $0.67(\mathrm{~ns})$ \\
\hline Birth weight (g) & $\begin{array}{c}3103.88 \pm 150.54 \\
2740-3250\end{array}$ & $\begin{array}{c}3076.66 \pm 155.42 \\
2750-3270\end{array}$ & 0.53 & $0.59(\mathrm{~ns})$ \\
\hline Positive Family history & $1(5.6 \%)$ & $2(11.1 \%)$ & 0.36 & $0.54(\mathrm{~ns})$ \\
\hline
\end{tabular}

Table (2) Comparison between NG and oral feeding groups as regard to intra- and post-operative analgesia and fluid therapy

\begin{tabular}{|l|c|c|c|c|}
\hline \multicolumn{1}{|c|}{ Variable } & NGT feeding & Oral Feeding & Test & P value \\
\hline IO fluids $(\mathrm{ml} / \mathrm{kg})$ & $30.88 \pm 3.66 ; 22-41$ & $30.16 \pm 3.68 ; 23-42$ & 0.58 & $0.56(\mathrm{~ns})$ \\
\hline IO fentanyl (mic/kg) & $3.11 \pm 0.27 ; 2.50-3.60$ & $3.02 \pm 0.37 ; 2.50-3.60$ & 0.86 & $0.39(\mathrm{~ns})$ \\
\hline IO-morphine $(\mathrm{mg} / \mathrm{kg})$ & $0.12 \pm 0.05 ; 0.06-30$ & $0.17 \pm 0.09 ; 0.07-0.40$ & 1.85 & $0.07(\mathrm{~ns})$ \\
\hline PO-morphine $(\mathrm{mg} / \mathrm{kg})$ & $0.13 \pm 0.08 ; 0-0.30$ & $0.23 \pm 0.13 ; 0.0-45$ & 2.77 & $0.009^{*}$ \\
\hline PO-paracetamol $(\mathrm{mg} / \mathrm{kg})$ & $32.50 \pm 15.55 ; 10-65$ & $51.66 \pm 28.43 ; 10-105$ & 2.50 & $0.017 *$ \\
\hline PO-ibuprofen & $14.44 \pm 8.72 ; 5.0-35.0$ & $26.38 \pm 14.43 ; 5-50$ & 3.01 & $0.005 *$ \\
\hline PO-feeding (ml/24h) & $137.22 \pm 13.52 ; 110-155$ & $59.72 \pm 18.74 ; 40-110$ & 14.22 & $0.001^{*}$ \\
\hline No of pain episodes & $3.17 \pm 2.03 ; 0.0-7.0$ & $4.77 \pm 2.86 ; 0.0-10$ & 1.99 & $0.047 *$ \\
\hline PO- fluids & - & $9.05 \pm 1.30 ; 7.0-11.0$ & 29.44 & $0.001^{*}$ \\
\hline
\end{tabular}


As regard to hospital stay duration (hours), it was significantly shortened in NGT feeding group when compared to oral feeding group $(47.55 \pm 15.33$ vs $78.66 \pm 18.04$ hours). On the other hand, there was no statistically significant difference between both groups as regard to surgical outcome, the good, fair and poor outcome was reported in $77.8 \%, 11.1 \%$, $11.1 \%$ respectively in NGT feeding group, while it was $66.7 \%, 22.2 \%$ and $11.1 \%$ with the same order in oral feeding group. Finally, postoperative complications were comparable between both groups; there were no complications in $72.2 \%$ in NGT feeding group and $61.1 \%$ in oral feeding group. Dehiscence was reported in 5.6\% and $11.1 \%$ in NGT and oral feeding groups respectively. Finally, fistula was reported in $22.2 \%$ and $33.3 \%$ in NGT feeding and oral feeding groups respectively (table 3).

Table (3) Comparison between NGT and oral feeding groups as regard to surgical outcome, hospital stay duration and $P O$ complications

\begin{tabular}{|c|c|c|c|c|c|}
\hline \multicolumn{2}{|c|}{ Variable } & NGT feeding & Oral Feeding & Test & P value \\
\hline \multirow{3}{*}{ Hospital stay duration (hr) } & $\begin{array}{c}47.55 \pm 15.33 ; \\
24-72\end{array}$ & $\begin{array}{c}78.66 \pm 18.04 ; \\
48-96\end{array}$ & \multirow{2}{*}{5.57} & $0.001^{*}$ \\
\hline \multirow{3}{*}{ Surgical outcome } & Good & $14(77.8 \%)$ & $12(66.7 \%)$ & \multirow{2}{*}{1.77} & \multirow{2}{*}{$0.41(\mathrm{~ns})$} \\
\cline { 2 - 4 } & Fair & $2(11.1 \%)$ & $4(22.2 \%)$ & \\
\cline { 2 - 4 } & Poor & $2(11.1 \%)$ & $2(11.1 \%)$ & \multirow{2}{*}{0.77} & \multirow{2}{*}{$0.67(\mathrm{~ns})$} \\
\cline { 2 - 4 } PO complications & None & $13(72.2 \%)$ & $11(61.1 \%)$ & \\
\cline { 2 - 4 } & Dehiscence & $1(5.6 \%)$ & $2(11.1 \%)$ & $6(33.3 \%)$ & \\
\cline { 2 - 4 } & Fistula & $4(22.2 \%)$ & \multicolumn{2}{|c|}{6} & \\
\hline
\end{tabular}

\section{DISCUSSION}

Oro-facial cleft is one of the most common congenital cranio-facial birth abnormalities (13). It was seen more frequently in Asians (1 to 2 in 1000) and less frequent among African Americans (0.5 to 1 in 1000) ${ }^{(14-15)}$. Malnutrition seems to be an added burden on these children in whom feeding problems already exists ${ }^{(3)}$. Thus, early surgical intervention is of utmost importance to correct the anomaly and enhance nutrition of the infant.

Results of the present study advocated nasogastric feeding rather than oral feeding, as it is associated with big amount of different food intake postoperatively, and statistical decrease of need for postoperative analgesia and shortened hospital stay.
These results can be attributed to the fact that, the attempt to feed fluids after surgical correction of cleft palate is usually associated with difficulties as infants often gag, choke, hold their breath, and scream due to pain. Urging babies to feed when in this state could lead to feeding aversions, aspiration pneumonia, nausea and vomiting ${ }^{(8)}$.

In addition, Kent and Martin reported that, NGT feeding had positive experiences for babies in hospital with fewer medical complications and a shorter hospital stay. They added that, their study showed that early feeding post-operatively reduced inpatient stay and that the use of immediate postoperative (NGT) appeared to speed the recovery of the babies, who required less analgesia. 
Furthermore, the same group of authors reported that, NGT feeding reduce post-operative pain and the giving of oral feeds and parents did not have to go through the difficulty and stress of feeding their babies with the associated risk of aspiration. In addition, the (NGT) offers a way of overcoming the prolonged hunger associated with pre-operative starvation ${ }^{(16) .}$

Furthermore, results of the present study are in agreement with previous work done by Carbajal et al. who suggested that nasogastric feeding decreased post-operative analgesic requirement and duration of hospital stay ${ }^{(17)}$.

Hughes etal.reported that, the intra-operative fluid requirements were not different statistically between groups. However, the amount of feed received in the first 24 hours post-operatively was statistically significantly different, with the NGT feeding group receiving approximately three times as much feed as the oral group. Nine of the oral group required supplementary intravenous fluids in the first 24 hours compared with none in the NGT group ${ }^{(18)}$. These results go in agreement with that of the present work. However, our results are in contradiction to the same group of authors in the same study, as they found that NGT feeding did not reduce analgesia consumption in the first 24 hours. In addition, it did not reduce the number of painful episodes although there was a wide range in the number of painful episodes manifested by each participant. In the present work we found that, NGT feeding reduced the total postoperative analgesia need and reduced pain episodes. The possible explanation of this contradiction may be attributed to different sample size and different age of their children as they included a 2 or more months' younger infants in their study when compared to the age of infants in the present study.

In conclusion: results of the present study provided a clinical evidence on the effectiveness of NGT feeding when compared to oral feeding postpalatoplasty for correction of cleft palate. It does increase consumption of foods and reduce analgesia requirements and the parents did not have to go through the difficulty and stress of feeding their babies with the associated risk of aspiration.

\section{REFERENCES}

1. Duartea A G, Ramosb B R and Cristina M. Feeding methods for children with cleft lip and/or palate: a systematic review_Braz J Otorhinolaryngol. 2016;82(5):602-609

2. Young JL, O'Riordan M. and Goldstein JA. What information do parents of newborns with cleft lip, palate, or both want to know? Cleft Palate Craniofac J 2001;38(1):55-8.

3. Ravi BK, Padmasani LN, Hemamalini AJ. and Murthy J. Weight Gain Pattern of Infants with Orofacial Cleft on Three Types of Feeding Techniques. Indian J Pediatr 2015; 82(7):581-585

4. Mizuno K, Ueda A, Kani K. and Kawamura H. Feeding behavior of infants with cleft lip and palate. Acta Paediatr. 2002;91: 1227-32.

5. Gopinath VK. and Muda WA. Assessment of growth and feeding practices in children with cleft lip and palate. Southeast Asian J Trop Med Public Health. 2005; 36:254-8.

6. Martin V. Pre- and post-operative nursing care. In Martin V, Bannister P (Eds) Cleft Care: A practical guide for health professionals on cleft lip and/or palate. Fivepin Publishing, Salisbury 2004; 83-94.

7. Sommerlad BC. Anatomy and Function. In Watson ACH et al (Eds) (2001) Management of Cleft Lip and Palate. Whurr Publishers, London 2001; 25-43.

8. Hockenberry M and Wilson D. Wong's Nursing Care of Infants and Children. Eighth edition. Mosby Elsevier, St Louis MO, 2007

9. Clarke S. Drug administration via nasogastric tube. Paediatric Nursing 2008; 20, 7, 32.

10. Wilkes-Holmes C. Safe placement of nasogastric tubes in Children. Pediatric Nursing 2006; 18, 9, 14-17.

11. Merkel S, Voepel-Lewis T. and Malviya S. Pain assessment in infants and young children: the FLACC scale. American Journal of Nursing 2002; 102, 10, 55-58.

12. Diah E, Lo LJ, Yun C, Wang R, Wahyuni LK. And Chen YR. Cleft oronasal fistula: A review of treatment results and a surgical management algorithm proposal. Chang Gung Med J 2007; 30:529-37. 
13. Ghonmode SW, Kalaskar AR, Kalaskar RR, Chole R, Bhushan P. and Ali FM. Vista of cleft lip and palate in India. J Evol Med Dental Sci. 2012; 1:1102-11.

14. Murray JC. Gene/environment causes of cleft lip and/or palate. Clin Genet. 2002; 61:248-56.

15. Mossey PA, Little J. Epidemiology of oral clefts: an international perspective. In: Wyszynski DF, editor. Cleft lip and palate. From origin to treatment. New York: Oxford University Press; 2002. p. 127-58.

16. Kent R, Martin V. Nasogastric feeding for infants who have undergone palatoplasty for a cleft palate. Pediatric Nursing 2009; 21(10): 24-29

17. Carbajal R, Veerapen S, Couderc S, Jugie M. and Ville Y. Analgesic effect of breast feeding in term neonates: randomized controlled trial. BMJ 2003; 326 (7379): 13.

18. Hughes J, Lindup M, Wright S, Naik M, Dhesi R, Howard R, Sommerlad B, Kangesu L, and Sury M. Does nasogastric feeding reduce distress after cleft palate after cleft palate repair in infants? Nurs Child Young People 2013; 25(9): 26-30. 